\title{
AS CONSTRUÇÕES DAS CIDADES SEGUNDO SEUS PRINCÍPIOS ARTÍSTICOS A PARTIR DA PRAÇA EM CAMILO SITTE
}

\author{
Júlio César da Silva
}

\section{APRESENTAÇÃO}

Na obra A Construção das Cidades segundo seus Princípios Artísticos, de Camillo Sitte marcou suas teorias urbanísticas ao tratar da dimensão estética das cidades tal qual obra de arte, ampliando a preocupação para além do que é atender as necessidades funcionais. A crítica é bastante profícua ainda na atualidade, pois as novas construções ficaram simplesmente técnicas perdendo o efeito artístico que fazia bem ao espirito; e ainda, a questão de até que ponto na modernidade as construções passaram a ser vistas do ponto de vista artístico somente, deixando, assim, a funcionalidade, a humanidade, de lado. Destarte, o sucesso desta obra se deu principalmente por tratar sobre a construção das cidades sobre a visão do cidadão, que transita pelas ruas, pelas praças, nos mais variados percursos, enxergando-a como uma somatória de fragmentos, para assim ter a visão totalizante da cidade. É claro que o ponto de partida de Sitte é a praça, pois, ela liga as partes, faz com que as partes sejam sentidas quando o que passa encontra seu espaço livre. É a praça que faz respirar, e se mensura o quanto já caminhou dentro da cidade. Ante o olhar espiritual deslizam praças, monumentos, imagens urbanas adoráveis e belas paisagens, e se pode fruir novamente o prazer de se demorar junto a tudo aquilo que é gracioso e sublime que, em outro momento, animava o espírito. Ou o desanimo pode encontrar na praça este suspiro.

As cidades antigas possuem uma beleza tão grande que faz bem ao espirito e não cansa seu expectador. É interessante também recolher essa visão otimista de Sitte sabendo que o atrai por ser belo, pode também possuir efeito contrário, mas mesmo assim o princípio da atração continuará a existir, e por isto o texto se salva mesmo diante do tosco, do rude que existe na cidade antiga. A admiração surge de qualquer maneira, e é capaz de mexer com o dia de qualquer pessoa que estivesse passando por momentos bons ou ruins.

O texto de Sitte já tem de antemão apresentada premissas que obedecem à máxima que intitula a obra. De modo poético, mas não descuidado, chama a Aristóteles para serventiar a seu propósito, pois foi o estagirita que resumiu os princípios da 
construção urbana ao dizer que uma cidade deve ser construída para tornar o homem ao mesmo tempo seguro e feliz, em outras palavras, uma cidade tem de ser construída com técnica, mas aliada a uma visão artística. As construções urbanas se tornaram uma questão técnica, onde o artístico é deixado um pouco de lado, mas, como adiantado, o contrário também pode ocorrer.Claro que o fato de que as construções mais modernas serem mais técnicas, não deve ser levada apenas com negatividade, condenando o que já foi aplicado neste âmbito, quem acredita que ainda pode ser feito construções com beleza artística, também deve se agraciar por tudo o que já foi feito. Daí, os exemplos e críticas do passado têm que coexistirem na mesma pessoa que projeta, a fim de que o desenho possa traduzir de fato o que é humano e interessado, traduzindo, deste modo, técnica, beleza, conhecimento e sobriedade.

Considerando esse contexto, Sitteapresenta um análise do aspecto técnicoartístico de cidades antigas e a ele mais contemporâneas, no intuito de mostrar os motivos de suas construções, possibilitando uma saída de resgate da tendência do modernismo técnico, árido, que aniquila, a seu ver, a beleza que acredita encontrar nas cidades antigas. Aborda estudos dos conjuntos urbanos e da localização de monumentos nos períodos mais recentes da Renascença e Barroco, relembra um pouco dos conceitos gregos e romanos que ajudam a compreender o conjunto urbanístico renascentista que podem ser uteis para analisar outros períodos.

Como objeto de estudo, analisa a praçana antiguidade na composição de espaços livres com edificações, usada para festejos e outras ocupações que poderia ganhar. Grande parte da vida pública acontecia ali, os mercados e feiras; os sacrifícios eram realizados ao relento dos templos, jogos e representações de teatro que eram realizados a céu aberto; até mesmo a moradia antiga segue por este caminho, onde tinhamum pátio descoberto rodeado de diversas salas e cubículos. Então, fica clara a mínima diferença entre os exemplos citados e as praças urbanas que atualmente perderam esse significado, porém, garantem maior circulação de ar e luz, provoca certa interrupção na constância dos conjuntos de moradias permitindo uma visão maior e melhor sobre as projeções arquitetônicas das cidades. Mas esta projeção plástica que se tem na maioria das praças modernas tira a vivência mais prolongada, para além da contemplação, para além da passagem fulgurante.

A partir de Vitrúvio se pode entender a clara a intuição que os antigos tinham acerca da identidade entre todas essas coisas. OFórum como melhor exemplo de praça, e nadescrição feita por Vitrúvio, pode-se observar que no Fórum de Pompéiacontendo 
as seguintes características: os edifícios públicos ocupavam maciçamente seus quatro lados, na parte mais estreita ao norte o Templo de Júpiter se estendia até a praça aberta. O fórum é cercado por colunas em dois andares, deixando livre o espaço central da praça, enquanto ao redor erguiam-se numerosos monumentos. O Fórum Romanopossui as mesmas características, mesmo que o fechamento de espaço seja de outra origem, os edifícios são igualmente construções monumentais, os espaços são como um tipo de salão de festas; os monumentos também são dispostos ao redor de sua borda.

A praça do mercado de Atenas, também é segueas mesmas regras do Fórum. Isso pode ser observado nas áreas dos grandes templos da Antiguidade grega de Elêusis e Olímpia. Na Acrópole de Atenas, pode-se perceber que a arquitetura, escultura e pintura fundiram-se como uma composição das artes plásticas, com uma plataforma elevada, envolta por muros altos, mas livre no centro, apresenta a forma primitiva tradicional. Isso não se trata apenas de um conjunto urbanístico, mas de uma verdadeira obra de arte formada ao longo dos tempos.

\section{A RELAÇÃO ENTRE AS CONSTRUÇÕES MONUMENTAIS E PRAÇAS}

No sul da Europa foi conservado, mesmo que em partes, os conjuntos urbanos antigos e muitos dos costumes de vida pública, as principais praças das cidades ainda se encontram fiéis ao mais variados aspectos até mesmo as mais recentes ao modelo do Fórum velho. Existem cidadelas antigas nas colinas italianas que são conservadas, e que na atualidade viraram pontos turísticos no sentido de 'vender' a ideia de vida pacata, doméstica, e isto se dá ao redor da praça.

Na Idade Média e na Renascença, as praças ricamente artísticas eram o orgulho e a alegria das cidades, eram o local ondese concentravam os movimentos públicos, festas, cerimônias oficiais, anuncio de leis. Conforme o tamanho da comunidade servia a essas necessidades práticas, também ocorriam às manifestações acordo com o tamanho de cada comunidade, serviam a essas necessidades práticas.A signoria funcionava como átrio da residência principesca, rodeada pelos palácios dos grandes senhores da região e cercada por monumentos e estatuas históricas, isso estava ligado ao desenvolvimento da praça da catedral como um modelo independente, que também incluía o batistério, a campanilha e o palácio, adiante ficava a praça laica. Ali quase sempre se encontrava uma loggia, que são construções arquitetonicamenteconstruídos para abrigar o guardas do espaço urbano. Um belo exemplo é a Loggia dei Lanzi em Florença. Tudo isso confirma o papel primordial que as praças livres podem exercer da 
cidadania no desenvolvimento, no desenrolar, no cotidiano da cidadania no espaço que segue para a publicidade bem como assistência da res pública. Mesmo na atualidade não se deixou de explorar o potencial artístico das construções como obras de arte, mas o que destoa nas duas novas capitais no Centro-oeste é a questão plástica levada ao extremo, que mais faz afastar e não suscitar a agradabilidade no citadinos.A Piazza Del Duomo em Pisa é uma dessas obras de arte da construção, é uma grandiosa obra de arte que possui ataque direto por magnifico efeito por sua belezaaté mesmo em alguém que pouco sabe de arte; a rendiçãopela simples contemplação de sua beleza arquitetônica se torna inevitável. E "ali não há nada que possa distrair nossas reflexões ou nos trazer à lembrança os afazeres cotidianos" (SITTE, 1992, p.27).

Nas construções modernas dificilmente pode ser observado combinações perfeitas entre os conjuntos urbanos, que possa privilegiar um trabalho marcado por confrontos visuais, em relação a isso. ASignoria tende a combinar de todas as maneiras possíveis os confrontos em favor de suscitar beleza, agradabilidade, convite para ficar, etc. Seguindo nessa linha de combinações, algo que se manteve intacto com o tempo foi a praça de mercado, que quase sempre compõe no conjunto da obra, umchafariz, um monumento que rememore algo um prédio público. "Na vida pública a Idade Média e da Renascença houve uma valorização intensa e prática das praças da cidade e uma harmonização entre elas e os edifícios públicos adjacentes" (SITTE, 1992, p.30). Seguindo essa linha crítica, sobre as praças na atualidade, pode-se afirmar que, muitas vezes a função das mesmas é apenas para estacionamento de automóveis, ou seja, sendo ignorado sua verdadeira função artística, de convívio, de rememorar, de relacionar-se com o espaço e suas edificações como conjunto único, ficando essa ausência de tudo o que pode ser frisado como particularidade da beleza artística das praças antigas.

As construções monumentais oferecem grande espaço para as esculturas. E para a ocupação dos espaços das mesmas, costumam ser formadas comissões que são responsáveis por definir os locais onde deverão ser colocadas as estatuas, mesmo após anos talvez não se encontre uma praça onde um monumento possa ser colocada de maneira satisfatória. Essa situação pode ser melhor entendida pela história de Davi de Michelangelo, em Florença. O local escolhida por Michelangelo para a estátua colossal foi àparede esquerda da principal entra do Palazzo Vecchio, permanecendo lá de 1504 a 1873. Segundo Sitte, todos que tiveram a oportunidade de ver a notável obra testemunharam o efeito prodigioso que ela causara, deu a impressão da praça ter tamanha reduzido, contudo proporcional.A oposição entre ontem e hoje consiste no fato 
de que sempre se procura as praças mais grandiosas para cada pequena estatua, ou seja, nem sempre um espaço grande reforça a beleza de alguma ornamentação, pelo contrário, pode neutraliza-lo. Um elemento diretamente relacionado a isso, conforme já mostrado, é de que os antigos colocavam suas ornamentações ao redor do muro de suas praças, pelo espaço comportar centenas de estatuas, encontraram um fundo favorável, ficando sempre em destaque, como foi demonstrado no caso do Davi. O mesmo não se pode perceber em relação aos palácios. As praças ora se tornam simples quintais por conta da grandiosidade predial, ou não são percebidas simplesmente por identidade própria, sempre estarão para a construção de destaque. A harmonia aclamada em relação a algumas praças não tem existido no sentido de elevar a praça em si, e concomitantemente seus mobiliários; ela tem sido colocada no centro para apontar para algo, e por mais que existe a defesa, no caso da Praça dos Três Poderes e da Praça dos Girassóis, a sensação inóspita toma os que vivenciam seus espaços, e a beleza aclamada é algo mais que se vê por ou imagens do que na assistência real daqueles espaços.

Uma praça bela, a princípio, teria a disposição de monumentos e imobiliários alocados de forma que relacionassem entre si de uma maneira facilitada, assim, a instalaçãopode ser vista a partir de um foco centralizador que atrai, e não o contrário. Por isto quando se refere à beleza das últimas praças referidas, aponta-se que o belo pertence muito mais à imagem do que ao objeto de fato. Mais frequentemente se torna a disposição de monumentos imobiliários no centro da praça, muitas vezes a escolha para a disposição desses monumentos, tais como chafarizes e estátuas, deixa um enigma de sentimento artísticos, naturais ou espontâneos que acontecia de maneira natural no passado. Atualmente, a praça moderna abraça o status de beleza plástica que não funciona de fato fora do desenho, além da maquete; o espaço constituído ganha outra estatura, se transforma em outra coisa que o desenho não dá conta. Segundo Sitte, às vezes, em outros tempos faziam uso de instrumentos meramente técnicos, réguas, compassos, ainda, usavam o talento natural, uma certa percepção que vai além do cálculo. Entregavam-se à uma fruição do espaço pela qual conseguiam traduzir o lugar pelo lugar. O que é contraponto diante de alguns processos criativos hodiernos, os quais preconizam a exigência de se ter um espaço livre simplesmente, ou uma praça para determinado fim urbanístico que não o é de fato, é puramente a obediência a uma regra. Não se olha para a praça de forma orgânica a partir do lugar, a praça moderna parece não pertencer ao locus que a endereça. Em um estudo mais detalhado de determinado caso destas criações naturais, podem-se fundamentar os efeitos positivos traduzindo-os 
em palavras, para clarear a racionalidade, notando que nesse aspecto, já se perdeu a naturalidade dos sentimentos no processo de construção desses conjuntos urbanos, de maneira que a intuição ficou prejudicada quando se trata de fazer uso deste dom natural.

Os monumentos e mobiliários não costumam se localizar nos principais eixos circulação de pessoas e nem no centro das praças, e sim ao redor de tudo isso. A composição deste espaço varia de cidade em cidade, ligado principalmente ao desenvolvimento histórico, a disposição de monumentos posteriores no geral segue padrões atuais e simétricos, enquanto os monumentos estabelecidos em bases mais antigos se encontram de forma mais assimétricas. Destaca-se as disposições do chamado SchöneBrunnen (Belo Chafariz) na praça do mercado de Nurembergue, e o chafariz na praça de mercado de Rothernburg na DerTauber, segue uma orientação oposta. Em grande parte das cidades alemãs predominam os modelos de Nurembergue, sendo mais raras similares à de Rothernburg, que dificilmente apresentam um monumento antigo no centro. Dos mais variados exemplos de monumentos, o da estátua equestre de GattamelataI, de Donatello, diante da Igreja de Santo Antônio, em Pádua é bastante instrutivo, não moderna, mesmo não sendo a melhor para objeto de estudo, por sua disposição na praça, pode-se notar o efeito admirável pela sua localização e não causaria o mesmo efeito se estivesse disposta no centro da praça. A estátua equestre de Pedro Ludovico Teixeira não estão centralizada na Praça Cívica em Goiânia, é periférica. Mas Funciona de bom grado, uma vez que está em uma das extremidades da praça às margens das avenida que circunda e distribui o tráfego que costeia a praça. Não era motivo da praça, foi colocada tardiamente. Uma vez que a escultura que é central carrega o peso de ser símbolo ideológico da fundação do Estado de Goiás, a saber, o Monumento às três raças.

Interessante é outro ícone estatuário localizado em uma encruzilhada de grande importância, O Anhanguera. Esta estátua de porte considerável anuncia 'Goianos, nobre estirpe dos Bandeirantes' na intersecção da Avenida Anhanguera com a Avenida Goiás. Esta pequena praça era florida e centralizava a estátua do Anhanguera, no entanto, o transito desta capital ficou caótico, e as reformas rodoviárias subsumiram a praça ajardinada. Mas a estátua ficou, sua base foi triplicada de tamanho e lhe deu mais imponência; "logo, à regra antiga de dispor os monumentos ao longo das bordas das praças, soma-se aquela de caráter nórdico, genuinamente medieval: os monumentos, em especial os chafarizes, devem ser dispostos em pontos intocados pelo trânsito da praça”. (SITTE, 1992, p. 38). 
Nos casos citados, fica claro o repúdio ao caminho de tráfego, sobretudo a eixos centrais para disposição desses monumentos.Pode ser observado que a coincidência entre as exigências dos trânsito e do efeito artístico é compreensível, pois, garante a liberdade da linha de trafego e por outro lado garante que a beleza artística possa ser contemplada visualmente. A regra do centro livre nas praças também é aplicada para edifícios e principalmente igrejas, que atualmente quase sempre colocadas no centro das praças contrariando as construções antigas. Na Itália, as igrejas eram construídas encostadas em outras estruturas ou encaixadas nelas. Exemplos tais como: A Igreja de S. Giustina é encostada em outro edifício; a de S. Antonio e a Del Carmine, em dois. Em Verona todas as igrejas são encaixadas em alguma edificação, pelos menos encostadas em algum. Na catedral em S. FermoMaggione, em S. Anastasia nota-se uma praça mais ampla frente ao pórtico principal. Sabe-se que cada edificação dessas tem sua história, mas todas possuem um efeito mágico diante dos olhos de quem a observa. Os exemplos citados em oposição ao sistema moderno precisam de um estudo mais detalhado sobre esse aspecto importante. Segundo Sitte,Roma possui um grande número de igrejas onde 41 delas são encostadas em outros edifícios em um lado, 96 em dois lados, 110 em três lados, 2 são obstruídas em outros edifícios em quatro lados e 6 são isoladas, totalizando 255 igrejas.Entre as 6 igrejas isoladas se encontram duas modernas, sendo uma protestante e outra anglicana, e outras 4 encontram-se na beirada ou esquina de uma praça.O centro do plano da igreja, assim como monumento, deveria coincidir com a área central da praça. $\mathrm{O}$ fato de as igrejas nunca terem sido construídas isoladas em Roma épraticamente uma regra que também ocorre em praticamente toda a Itália, que em muitas cidades as Igrejas são construídas encaixadas em outros edifícios, como em Pávia, Vicenza; Cremona, Milão, Veneza, Nápoles, Palermo, Ferrara e inúmeras outras.

A praça da catedral de Brescia se enquadra ao sistema mencionado acima, apesar de sua disposição singular, sua fachada serve como limite da praça. A aparência moderna é contraria a este sistema bem integrado, mas provavelmente executado com essa intenção. Do ponto de vista do edifício, ela é a mais desfavorável, porque o efeito da obra não se concentra em lugar apenas se dispersando ao redor, sendo desfavorável também na visão de quem a construiu, pois exigiu somas maiores para composição arquitetônica e ornamental de suas fachadas. Apesar de esta composição ser comprovadamente ruim sob vários aspectos, de toda a história de igrejas indicarem o caminho oposto, todas as igrejas que vem sendo construídas pelo mundo estão 
localizadas no centro das praças de maneira isolada.O mesmo é válido para teatros e prefeituras, etc. Um espaço vazio é monótono, anulando qualquer efeito artístico. Atualmente, apenas em gravuras pode-se observar a magnitude das pedras dos palácios florentinos, mesmo se vistos a partir de pequenas ruas, praças, que dependendo da posição que se observa pode-se ter uma variedade de efeitos. Sobre a obsessão pelo isolamento das edificações, o autor cita Reinhard Baumeister, que em seu manual da construção urbana, eleva as categorias de normas com as seguintes palavras: "Construções antigas devem ser preservadas, mas desimpedidas e restauradas". Então se deduz que, através de reformas em sua volta, essas obras devam ser isoladas e alinhadas aos eixos das ruas.

\section{A COESÃO DAS PRAÇAS}

Quando se estuda essa característica particular nas praças medievais e renascentistas, o que acontece especialmente em praças da na Itália, logo se percebe que ela é a responsável pelo extraordinário efeito harmônico do conjunto que comunica com a vida local, mesmo que aludindo a alguma grandeza específica: elevar a Deus, o Estado, algum herói, uma família, etc. A construção urbana moderna também ignora este que é o mais importante e imprescindível requisito do efeito artístico orgânico, no sentido de que aponta para a beleza e eleva o lugar pela disposição do próprio lugar. Este termo se sustentou na tradição, favorecido ainda pela falta de largura das ruas que indicavam pouca necessidade de trafego, mas a beleza e a sua visão se manifestava de diversas maneiras não importando a condição. A questão seria se, mesmo que o processo de industrialização que apontou para outros rumos no que se refere à construção e a materialização da beleza, o modernismo não teria dado conta de apresentar nas suas linhas simples o que de fato é orgânico. A crítica salienta a falta de compromisso com a vivência que insurge em desenhos belos, simples, mas que a força de argumento que tenta sustentá-los na prática.

A partir de um conjunto de residências, é encontrado um espaço diante destas edificações, essa solução se adequa à necessidade de um preenchimento continuo a sua volta de edifícios, isto pode ser observado na pequena praça de S. Giovanni em Brescia, que apresenta uma segunda rua, porém, mantendo-se uma visão limitada sobre o edifício principal.Não é por acaso que encontramos um sistema de saída de ruas drasticamente opostas ao moderno em todas as praças. Entre os antigos cada ângulo da praça a medida do possível deveria desembocar, apenas uma única rua e se couber, 
outra perpendicular que desemboca na primeira, onde já se pode observar a praça.Observando com mais atenção é fácil compreender que este tipo de rua, representa uma escolha melhor adequada, pois de qualquer ponto da praça se tem uma única visão para fora dela, ocorrendo uma única forma de coesão de todo o contorno no conjunto de edificações. O segredo consiste no fato de as ruas serem perpendicular às linhas de visão e não paralelas, isso já era aplicado durante a Idade Média. Entre os exemplos mostrados aqui, a praça da catedral de Ravenaé a que melhor mostra essa composição. A Piazza S. Petro em Mântua mostra esse mesmo tipo com maior clareza. A Praça de S. Clemente corresponde em partes apenas. Um panorama do Mercado Novo de Viena demonstra como é possível se obter uma visão fechada a despeito do curso das ruas.

Um motivo empregado para se obter tal efeito é a fachada ampla sob as edificações, que possibilita excelente coesão da vista, clareando a diversificação da quantidade e do tamanho das aberturas de acordo com a intensidade de trafego no local. E Florença fornece novamente o melhor exemplo, PorticodegliUffizi, próximo à Signoriapermite uma bela vista sobre o Rio Arno. Na Itália poucas cidades deixaram de fazer uso desse procedimento, tais comoLanggasserTor, em Dantzig, com três arcos de passagem e sob uma construção de palácio sutilmente articulado e também, de sutil proporção. Com a sua beleza devido à medida dos arcos que possibilitaram o transito, a Praça da Josephsplatz, em Viena. Na Antiguidade, temos o pórtico de acesso ao Fórum de Pompéia.

Todas as disposições e formas arquitetônicas citadas agrupavam-se espontaneamente como um sistema completo para o fechamento de praças em contraste ao que se vê atualmente, que é manter as praças abertas, remetendo ao aniquilamento das praças antigas, perdendo-se o efeito harmonioso e coeso de todo o espaço.

\section{DIMENSÃO E FORMA DAS PRAÇAS}

Analisando sob o aspecto do formato entre as praças e seus principais edifícios, têm-se dois tipos de praças, as de largura e as de profundidade, o que as identifica como tais categorias é o ponto de vista de quem as observa. De acordo com esses parâmetros, a Praça de S. Croce em Florença pode ser enquadrada em ambas as categorias, onde sua composição está disposta em relação à fachada principal da igreja, sendo esta a melhor direção para se observar a praça. 
Ao se analisar com maior precisão pode-se observar que as praçasde profundidade dão uma impressão de amplitude quando o edifício principal está ao fundo e apresenta dimensão semelhanteà praça. Uma praça diante de um edifício onde suas dimensões predominam a largura, característica própria de prefeituras, deve manter uma forma claramente mais larga. A Piazza Reale, em Módena, exemplifica este caso.Assim como o formato,a dimensão das praças possui uma relação de proporção com os edifícios que as cercam, porém de maneira sutil, mas nitidamente perceptível. Não se pode receber todo o efeito de grandiosidade de uma praça na mesma proporção de suas dimensões reais, esse efeito pode crescerse for acrescentado alguns metros na largura dessa praça, seria pouco nítido em uma praça de porte grande, se teria a perda total da relação comum entre a mesma e os edifícios que a cercam. Em cidades modernas, as praças gigantescas existem sem causar o verdadeiro efeito de uma praça urbana por não ter mais uma relação de igualdade entre suas dimensões e os edifícios que a cercam. Exemplos: o Campo de Marte de Paris e o de Veneza, e as Piazza d'Armi, em Trieste e Turim.

Se analisar as medidas reais de algumas das maiorese das menores praças de uma cidade qualquer, será observado que não existe nenhuma relação entre o efeito causado pela dimensão de uma praça e seu tamanho real. A boa proporção entre os tamanhos da praça e dos edifícios é extremamente importante, podendo não ser definida com exatidão, por estar submetida a oscilações frequentes e consideráveis, pois nas construções modernas a técnica substitui o desenvolvimento histórico dessas praças, e devido a esta importância das medidas absolutas, passou a ser utilizada uma escala idêntica para todos os esboços e serem aplicadas na medida do possível.Em relação a isso, Sitte cita as seguintes regras:

1) As principais praças das cidades grandes são maiores que as das cidades pequenas;

2) As principais praças de todas as cidades têm dimensões incontestavelmente maiores, enquanto as demais devem ser menores;

3) A dimensão das praças incluídas na categoria 2 (segundo o cálculo da média do fato dado na categoria 1) está em proporção com a dimensão dos edifícios dominantes em cada uma delas, em outras palavras, a altura do edifício encontra-se em relação proporcional com as dimensões da praça. 
Seguindo parâmetro, observa-se que a simples altura do principal edifício da praça, em uma aproximação grosseira, pode ser considerada como a menor dimensão possível para ela, assim, como da mesma maneira, o dobro da altura do edifício corresponde à dimensão máxima da praça para que seja obtido um efeito satisfatório. Como regra, quanto maior os espaços, menor o efeito, pois caso contrário os edifícios e os monumentos não tem como garantir sua imponência.

Sitte cita uma doença nervosa intitulada de agorafobia que se caracteriza por as pessoas deixarem de usar o espaço da praça por causa do tamanho, emitem sensação de desconforto, apontam para a falta de comodidade no lugar. Esses percalços estão ligadas diretamente às praças modernas, e se trata de algo que é tão comum nos dias de hoje nas cidades modernas que não desperta grande atenção, se torna mais uma espécie de sentimento ligado ao gosto no imaginário de quem percebe essa confluência de sentimentos. Mas o que se via nas praças antigas é que eram acolhedoras, passavam a sensação de gigante na mente de quem a observa por sua grandiosidade artística que ocupa o tamanho real.

\section{IRREGULARIDADE DAS PRAÇAS ANTIGAS}

Sob ponto de vista artístico, a regularidade das praças e o alinhamento das ruas serem retas e mais longas o possível, trata-se de uma preocupação inútil. A Piazza Eremitani, em Pádua, as praças da catedral em Siracusa e em Pádua e a Piazza S. Francesco em Palermo, a origem das irregularidades dessas praças encontra-se em seu gradual desenvolvimento histórico.Qualquer cidade poderia oferecer vários exemplos de aspecto de irregularidades em suas praças que ao longo do tempo contribuíram para a beleza artística da mesma, mesmo porque não se notam normalmente os traçados oblíquos, considerando apenas as retas e ângulos. Muitas pessoas já visitaramou conhecem por imagens a famosa Piazza d'Erbe em Verona, mas poucos têm consciência de suas significativas irregularidades. Também, podemos citar a comparação entre a planta real e a representação na mente de qualquer pessoa da Piazza S. Maria Novella em Florença, a maioria das pessoas guardam dela uma imagem quadrada apesar de ter cinco lados, isso acontece porque é possível avistar apenas três dos cinco lados de uma vez.

É bastante notável como as irregularidades das praças antigas não têm uma aparência ruim comparado ao efeito causado pelos ângulos irregulares das edificações modernas, isso acontece devido às cidades antigas terem suas irregularidades apenas no 
projeto, mas nas suas edificações isso não ocorre por sofrerem um desenvolvimento in natura, por isso se nota apenas o que chama atenção para o campo de visão. Nas praças de Siena e na Praça de S. Siro, em Gênova, fica claro que a profundidade das fachadas das igrejas foram abertas com o propósito de garantir uma visão boa sobre as estruturas principais.

A pouca importância quanto à simetria e regularidade exata nas criações arquitetônicasse esbarra no efeito harmônico de todaassimetria de construções não modernas. Simetria, termo de origem grega, um dos principais fatores que gera a beleza que harmoniza a partir de combinações e proporções regulares.Na Antiguidade tinha sentido diferente do moderno conceito, Vitrúvio descreveu: "Da mesma maneira, a simetria é uma sensação agradável proveniente dos elementos da própria obra e uma relação proporcional entre as partes separadas e a forma da figura toda". Na arquitetura proporção era apenas uma qualidade de caráter benéfico nas estruturas, avaliada pelas sensações e simetria tinha o mesmo significado expressas em números exatos. Esse seguiu por toda a Idade Média, adquirindo seu sentido moderno quando surgiram os primeiros esboços arquitetônicos dos mestres góticos. Na Renascença este termo passou a ser aplicado com esse sentido até os dias de hoje, sendo aplicado nas edificações.

\section{CONJUNTOS DE PRAÇAS}

Existe com frequência a ocorrência de praças colocadas uma ao lado de outra, bastante comum na Itália, onde se pode observar que no centro da cidade possui um conjunto de praças juntas a edifícios de grande importância, e as praças isoladas são a exceção. Isso está diretamente relacionado ao fato do fechamento das praças e das igrejas e palácios serem encaixados em outros edifícios, deixando claro que a Piazza Grande de realçar a fachada lateral da igreja, ou seja, cada partícula desse conjunto tem uma função que complementa a outra arquitetonicamente. Esse tipo de exemplo ressalta a impressão de que cada uma das fachadas das edificações motivou a formação das praças que a cercam, aumentando o efeito que causa sobre o observador. Sem dúvida esses conjuntos de praças permite a completa apreciação de suas belezas arquitetônicas, através de um conjunto harmônico, Sitte sustenta que isso comprova a sabedoria que os antigos tinham em alcançar a grandiosidade artísticade maneira econômica, ficando assim, claro que este método do conjunto de praças sendo o melhor para aproveitamento de espaços nas construções monumentais. 
A Piazza d'Erbe,em Mântua, apresenta um conjunto de praças semelhante, desenvolvida como praça de largura diante a igreja uma praça de profundidade. $\mathrm{O}$ mesmo acontece com a praça da catedral em Perúgia, sobrepujada por uma praça grande e tem uma menor em frente à Catedral. Arquitetonicamente, a Signoria é a uma praça notável do, pois, nela estão reunidos todos os motivos de construção urbana antiga, por sua forma, dimensão, praças, espaço das ruas, monumentos, etc., cada um desses itens encontra-se de maneira que se sente todo o efeito da experiência artística por vias de tentativa de compreensão do arquitetônico. "E é por estar oculto todo o aparato artístico responsável pela realização de tudo isso que jamais saturamos nosso olhar ao admirarmos este conjunto". (SITTE, 1992, p.71).

O centro de Veneza possui um dos mais belos conjuntos de praças formado pelas praças de S. Marcos e a Piazzetta, sendo a primeira uma praça de profundidade em relação à Igreja de $\mathrm{S}$. Marcos e de largura em relação às procuradorias, a segunda de largura em relação à frente do Palácio dos Doges, principalmente de profundidade em relação à vista sobre o Grande canal com S. Giorgio Maggiore ao fundo. Sem dúvidas essa obras deixariam de ter esse efeito sedutor caso fossem criadas no sistema moderno, separadas e com eixos geométricos, perdendo todo o efeito coeso entre si. A formação da Praça de S. Marcos e suas praças vizinhas é conveniente a todas as regras citadas. Ao fotografar essas praças de diferentes ângulos, se pode obter um efeito criado pelo movimento de uma praça a outra, daí se obtendo sempre uma composição diferente. Surge a premissa que duvida se é a mesma praça.

\section{EXCURSO}

Não se quer colocar a seguinte proposição como tese última, mas o fato de se ter a plástica da cidade domada pela tecnologia ‘não-humana' acima do ‘humano' fez com que características mais pertinentes à sensibilidade do homem desaparecem da cidade. Existem circunstâncias nas quais que se pode pensar para que tipo de ser tal espaço foi feito. O momento de se encontrar em um espaço no qual se pode respirar, no qual se pode ser surpreendido constantemente é substituído pela grandiosidade espacial e traço seco do espaço moderno praça. Não são mais os paços do homem que encontram a praça, é pela janela do carro que se a vê.

A proximidade com as casas, a formação de um certo conjunto harmônico palácio-praça e a assistência fácil pelo passante foram deixados de lado nos projetos modernos, quer tenha sido por instinto ou propositalmente. Com isto, atualmente, se 
pode ver dois quadros ou mais: praças belas e praças secas. O belo aqui partilha da sensibilidade simples, mesmo que arrojada e plena de ornamentos; sendo que o seco se refere ao traço simples que chama a atenção para se distanciar do mesmo. Pode ser que tal análise já esteja em si coberta de alguma ideologia partidária de um determinado estilo, contudo, a praça deve apresentar elementos que dialoguem com mais proximidade com que a assiste, eis parte basilar de sua gênese antes de ser puramente plástica. 